www.jmscr.igmpublication.org

Impact Factor 5.84

Index Copernicus Value: 71.58

ISSN (e)-2347-176x ISSN (p) 2455-0450

crossref DOI: _https://dx.doi.org/10.18535/jmscr/v5i10.132

Journal Of Medical Science And Clinical Research

IGM Publication

An Official Publication of IGM Publication

\title{
The Prophylactic Effect of Timing of Dexamethasone on Postoperative Nausea and Vomiting in Patients Undergoing General Anaesthesia - A Randomised Double Blinded Placebo Controlled Study
}

\author{
Authors
}

\author{
Dr E. Ralleen Jacob ${ }^{1}$, Dr N.K.Sekaran ${ }^{2}$
}

${ }^{* 1}$ Post Graduate Student, Dept of Anaesthesia, Rajah Muthiah Medical College and Hospital,

Chidambaram, Tamil Nadu, India

${ }^{2}$ Professor, Dept of Anaesthesia, Rajah Muthiah Medical College and Hospital, Chidambaram, Tamil

$\mathrm{Nadu}$, India

\begin{abstract}
Introduction: Patients continue to experience Post Operative Nausea and Vomiting as one of the most distressing problem, inspite of the recent advances in anaesthesia that tends to reduce the adverse outcomes. Around 20\%-30\% of patients undergoing general anaesthesia experience post operative nausea, vomiting or both. Post operative nausea and vomiting (PONV) was defined as nausea or vomiting within 24 hrs of surgery. The general incidence of vomiting was about $30 \%$, the incidence of nausea was $50 \%$, and in case of high-risk patients, the PONV rate can be as high as $80 \%$. When PONV was not taken care of, it may result in prolonged post anaesthesia care unit (PACU) stay which significantly increased the health care costs.

Aim: To decrease the incidence of postoperative nausea and vomiting in patients undergoing general anaesthesia upon timing of prophylactic administration of dexamethasone.

Materials and Methods: Patients of age group 25-45 years who are scheduled for elective surgeries under general anaesthesia were identified as target population. Excluded were the patients with the history of motion sickness or any gastro oesophageal reflux disorders, patients who had received antiemetics within 48 hours before surgery, duration of surgery exceeding more than 4 hours and pregnant or menstruating women. At one minute before the induction of anaesthesia, Group 1 received $8 \mathrm{mg}(2 \mathrm{ml})$ of IV Dexamethasone, whereas Groups 2, 3 received $2 \mathrm{ml}$ of $\mathrm{IV}$ saline. At the end of administration of anaesthesia, ie. After tracheal extubation, Group 2 received $8 \mathrm{mg}(2 \mathrm{ml})$ of $I V$ Dexamethasone whereas Groups 1,3 received $2 \mathrm{ml}$ of $\mathrm{IV}$ saline. The randomised process and the identity of the study drug were blinded from the patients, the anaesthesiologists during surgery.

Results: The incidence of PONV was evaluated. During the postoperative period of $0-2$, patients in Group 1 reported a less frequent incidence ofPONV(15\%) than those in Groups 2 and 3 (50\% and 52.5\%, respectively). Patients in Group 1 also requested less rescue antiemetic (7.5\%) than those in Groups 2 and 3 (32.5\% and $37.5 \%$, respectively). During the postoperative period of 2-24 h, patients in Group 1reported less frequent incidences of PONV (17.5\%), patients in Group 2 reported $28 \%$ incidence of PONV. Both requested rescue anti emetics of about 10\% and 20\% respectively. Patients in Group 3 reported $50 \%$ incidence of PONV and $32.5 \%$ patients requested rescue anti emetics.

Conclusion: In conclusion, the prophylactic IV administration of dexamethasone immediately before the induction, rather than at the end of anaesthesia, was more effective in preventing PONV.

Keywords: Postoperative nausea and vomiting, Dexamethasone.
\end{abstract}




\section{Introduction}

Patients continue to experience Post Operative Nausea and Vomiting as one of the most distressing problem, inspite of the recent advances in anaesthesia that tends to reduce the

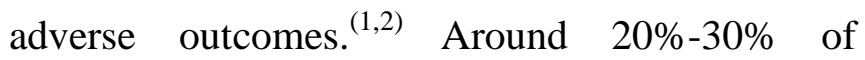
patients undergoing general anaesthesia experience post operative nausea, vomiting or

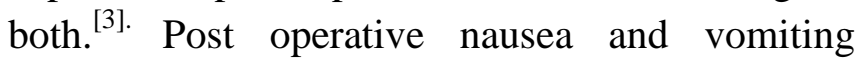
(PONV) was defined as nausea or vomiting within $24 \mathrm{hrs}$ of surgery. The general incidence of vomiting was about $30 \%$, the incidence of nausea was $50 \%$, and in case of high-risk patients, the PONV rate can be as high as $80 \% .^{[4,5,6]}$ When PONV was not taken care of, it may result in prolonged post anaesthesia care unit(PACU) stay which significantly increased the health care costs. Moreover, the leading cause of unanticipated hospital admission after elective surgeries was PONV. ${ }^{[7]}$ The goal of PONV prophylaxis was therefore to decrease the incidence of PONV and thus patient-related distress and reduce health care costs. ${ }^{[8]}$ Several guidelines on the management of PONV have been published. However, they are targeted for a specific surgical population or have not been updated in recent years. ${ }^{[9,10,11]}$

Subsequently many studies came up with the proof that Dexamethasone was effective in reducing the incidence of $\mathrm{PONV}$ in patients undergoing Thyroidectomy, Abdominal Hystrectomy, Adenotonsillectomy, Laparoscopic Cholecystectomy. ${ }^{[13-16]}$ Despite the presence of such studies, the optimal timing of Dexamethasone administration either before inducing the patient or around extubation was less well understood.

\section{Methodology}

After obtaining institutional ethical committee approval, patients of ASA physical status I and II between the age group 25-45 years scheduled to undergo elective surgeries under general anaesthesia were included. Excluded were the patients with the history of motion sickness or any gastro oesophageal reflux disorders, patients who had received anti emetics within 48 hours before surgery, duration of surgery exceeding more than 4 hours and pregnant or menstruating women. We expected a $30 \%$ difference among groups in the proportion of patients who complained of nausea or vomiting. The $\alpha$ error was set at 0.05 (twosided) and the $\beta$ error at 0.10 . Analysis showed that a minimum of 35 patients per group would be sufficient. We enrolled 40 patients per group to get a total sample size of 120 .

Before the study, patients provided detailed medical histories and demographic information, including age, weight, height, drug consumption, and last menstrual period. At one minute before the induction of anaesthesia, Group 1 received 8 $\mathrm{mg}(2 \mathrm{ml})$ of IV Dexamethasone, whereas Groups 2, 3 received $2 \mathrm{ml}$ of IV saline. At the end of administration of anaesthesia, ie. After tracheal extubation, Group 2 received $8 \mathrm{mg}(2 \mathrm{ml})$ of IV Dexamethasone whereas Groups 1, 3 received $2 \mathrm{ml}$ of IV saline. The randomised process and the identity of the study drug were blinded from the patients, the anaesthesiologists during surgery. The anaesthetic technique and surgical procedures were identical in all patients. Anaesthesia was induced with $5 \mathrm{mg} / \mathrm{kg}$ IV Thiopentone, $0.2 \mathrm{mg}$ of IV glycopyrrolate, and $2 \mathrm{mg} / \mathrm{kg}$ IV fentanyl. Tracheal intubation was facilitated by the administration of $2 \mathrm{mg} / \mathrm{kg}$ IV Succinylcholine. Anaesthesia was maintained with to $2 \%$ sevoflurane (inspired concentration) in oxygen along with nitrous oxide and additional vecuronium. Supplemental analgesia was provided with 50- to 100-mg IV boluses of fentanyl. Abdominal total hysterectomy (with or without oophorectomy), Laparoscopic Appendicectomy, Laparoscopic Cholecystectomy, Total Thyroidectomy, Modified radical mastectomy were some of the common procedures performed in patients. At the cessation of the surgery, 0.01 $\mathrm{mg} / \mathrm{kg}$ of IV glycopyrrolate and $0.5 \mathrm{mg} / \mathrm{kg}$ of IV neostigmine were administered for reversal of muscle relaxation and the patient was extubated.

After surgery, patients were immediately transported to the post anaesthetic care unit 
(PACU) where patients were observed for 24 hours. During their stay in the PACU $(2 \mathrm{~h})$, vital signs, such as blood pressure, heart rate and respiratory rate were monitored every 15 minutes and oxygen saturation was monitored continuously.

Patients were transferred to a ward for further observation 2 hours later. Pain intensity was rated by patients by using the visual analog scale (VAS; at 1 hour intervals during their stay in PACU and at 4 hour intervals in the ward (except during sleep). When a patient complained of pain, $75 \mathrm{mg}$ IM Diclofenac was given as a single dose to achieve patient comfort. Nausea and vomiting were assessed immediately after surgery and at 30-min intervals in the PACU for 2 hours. In addition, nausea and vomiting were evaluated every 4 hours (except during sleep) by direct questioning or by spontaneous complaint of the patients. Nausea and vomiting were evaluated on a 3 -point ordinal scale $(0=$ none, $1=$ nausea, and 2 $=$ vomiting). No distinction was made between vomiting and retching (i.e., a retching event was considered as a vomiting event). Patients who complained of nausea earlier and vomited later were included under vomiting only and not under nausea. When vomiting occurred or by patient's request, $4 \mathrm{mg}$ IV Ondansetron was given.

A series of one-way analyses of variance was conducted to examine differences among the three study groups with respect to parametric variables. If a significant difference was found, the Bonferronit-test was used to detect the intergroup differences. The Kruskal-Wallis test was used to determine differences among the three groups with respect to nonparametric variables, followed by the Mann-Whitney ranked sum test for intergroup differences. Categorical variables were analyzed by using a series of $3 \times 2 \chi^{2}$ tests to determine differences among the three groups, followed by $2 \times 2 \quad \chi^{2}$ tests for intergroup differences. All follow-up analyses were corrected for the number of simultaneous contrasts by using the Bonferroniadjustments. A $P$ value of $<0.05$ was considered significant.

\section{Results}

All 120 patients completed the study. There were no significant differences among the three groups with respect to age, weight, height, types of surgery, duration of anaesthesia and surgery, and the total of perioperativefentanyl doses (Table1,2). No patient demonstrated arterial oxygen saturation of $<90 \%$. The type of surgeries done under general anaesthesia in all the three groups were similar (Table 3). Patients in the three groups consumed similar amounts of rescue analgesic and reported similar VAS pain scores (0-2 h, Table $4,5)$. During their stay in the ward $(2-24 \mathrm{~h})$, the number of patients who consumed Diclofenacwere 3, 2, and 5 (median) in Groups 1, 2 , and 3, respectively, and the VAS pain scores were 1.5, 2.5, and 2 (median) in Groups 1, 2, and 3 , respectively. Because both nausea and vomiting present the same unpleasant physical reaction, the only difference being the severity, we used a total incidence of nausea and vomiting to present PONV (Table 6,7). The percent of patients requesting rescue antiemetics in each group was also calculated. During their stay in PACU $(0-2 \mathrm{~h}$ postoperatively), patients in Group 1 reported a significantly less frequent incidence of PONV and requested less rescue antiemetics than those in Groups 2 and 3 (Table 8). During the observatory period of 2-24 h (in the ward), patients in Groups reported a significantly less frequent incidence of PONV and requested less rescue antiemetics than those in Groups 2, 3 (Figure 1). 
Table 1: Demographic Data

\begin{tabular}{|l|c|c|c|c|}
\hline Variables & $\begin{array}{c}\text { GROUP 1 } \\
\text { (Preinduction) }\end{array}$ & $\begin{array}{c}\text { GROUP 2 (End Of } \\
\text { Anaesthesia) }\end{array}$ & $\begin{array}{c}\text { GROUP 3 } \\
\text { (Placebo) }\end{array}$ & \multirow{2}{*}{ P value } \\
\cline { 1 - 4 } Age(Years) & $36(30-42)$ & $32(26-38)$ & $35(26-44)$ & \\
\cline { 1 - 4 } Weight(Kg) & $60(52-78)$ & $54(48-69)$ & $56(46-74)$ & \multirow{2}{*}{$\mathrm{p}>0.05$} \\
\cline { 1 - 4 } Height(cms) & $154(140-171)$ & $162(148-180)$ & $158(150-174)$ & \\
\cline { 1 - 4 } Male & $65 \%(26)$ & $70 \%(28)$ & $45 \%(18)$ & \\
\cline { 1 - 4 } Female & $35 \%(14)$ & $30 \%(12)$ & $55 \%(22)$ & \\
\hline Smokers & $55 \%(22)$ & $42.5 \%(17)$ & $32.5 \%(13)$ & \\
\hline
\end{tabular}

Table 2: Anaesthesia and Surgical Variables

\begin{tabular}{|l|c|c|c|c|}
\hline Variables & Group 1 & Group 2 & Group 3 & \multirow{2}{*}{ P value } \\
\hline Duration of anaesthesia(min) & $150(140-210)$ & $142(134-194)$ & $162(156-223)$ & \\
\cline { 1 - 5 } Duration of Surgery(min) & $128(134-190)$ & $134(118-180)$ & $150(130-197)$ & \multirow{2}{*}{ p $\mathbf{0 . 0 5}$} \\
\cline { 1 - 5 } Total amount of fentanyl used & $140(120-150)$ & $130(110-130)$ & $150(120-160)$ & \\
\hline
\end{tabular}

Table 3: Type of surgeries done

\begin{tabular}{|c|c|c|c|c|}
\hline Type of Surgeries & Group 1 & Group 2 & Group 3 & $P$ value \\
\hline Otolaryngologic & $7(17.5)$ & $10(25)$ & $8(20)$ & \multirow{5}{*}{$\mathrm{P}>0.05$} \\
\hline Orthopaedic & $11(27.5)$ & $9(22.5)$ & $13(32.5)$ & \\
\hline Laparoscopy & $9(22.5)$ & $8(20)$ & $7(17.5)$ & \\
\hline Laparotomy & $10(25)$ & $11(27.5)$ & $9(22.5)$ & \\
\hline Others & $3(7.5)$ & $2(5)$ & $3(7.5)$ & \\
\hline
\end{tabular}

Table 4 : VAS Scores during the PACU Stay

\begin{tabular}{|l|c|c|c|c|}
\hline \multirow{2}{*}{ TIME } & \multicolumn{3}{|c|}{ VAS Scores } & \multirow{2}{*}{ P value } \\
\cline { 2 - 4 } & GROUP 1 & GROUP 2 & GROUP 3 & \\
\hline $0-2 \mathrm{hrs}$ & $3.5(3-5.5)$ & $4(3.5-6)$ & $4(3-6)$ & \multirow{2}{*}{0.248} \\
\hline $2-24 \mathrm{hrs}$ & $1.5(1-3.5)$ & $2.5(1.5-3.5)$ & $2(1.5-3)$ & \\
\hline
\end{tabular}

Table 5: Analgesic consumption during the PACU Stay

\begin{tabular}{|l|c|c|c|c|}
\hline \multirow{2}{*}{ TIME } & \multicolumn{3}{|c|}{ Analgesic Consumption } & \multirow{2}{*}{ P value } \\
\cline { 2 - 4 } & GROUP 1 & GROUP 2 & GROUP 3 & \\
\hline $0-2 \mathrm{hrs}$ & $10(25)$ & $12(30)$ & $16(40)$ & \multirow{2}{*}{0.115} \\
\hline $2-24 \mathrm{hrs}$ & $3(7.5)$ & $2(5)$ & $5(12.5)$ & \\
\hline
\end{tabular}

Table 6: Incidence of nausea and vomiting in PACU

\begin{tabular}{|c|c|c|c|c|}
\hline $\begin{array}{l}\text { IN PACU } \\
\text { (0-2HRS })\end{array}$ & Group 1 & Group 2 & Group 3 & $P$ value \\
\hline Nausea & $4(10)$ & $12(30)$ & $13(32.5)$ & $1: 2-\mathrm{p}$ value $<0.01$ \\
\hline Vomiting & $2(5)$ & $8(20)$ & $8(20)$ & $1: 3-\mathrm{p}$ value $<0.01$ \\
\hline Total & $6(15)$ & $20(50)$ & $21(52.5)$ & $2: 3-\mathrm{p}$ value $>0.05$ \\
\hline
\end{tabular}

Values are number of patients (\%). $n-40$ for each group.

PACU - Post Anaesthetic Care Unit.

$* P$ value using $3 \times 2 \chi^{2}$ test followed by $2 \times 2 \chi^{2}$ test. 
Table 7: Incidence of nausea and vomiting in ward

\begin{tabular}{|c|c|c|c|c|}
\hline $\begin{array}{l}\text { IN WARD } \\
(2-24 \text { HRS })\end{array}$ & Group 1 & Group 2 & Group 3 & $P$ value \\
\hline Nausea & $4(10)$ & $6(15)$ & $12(30)$ & $1: 2-\mathrm{p}$ value $<0.01$ \\
\hline Vomiting & $3(7.5)$ & $7(17.5)$ & $8(20)$ & $1: 3-\mathrm{p}$ value $<0.01$ \\
\hline Total & $7(17.5)$ & $13(32.5)$ & $20(50)$ & $2: 3-\mathrm{p}$ value $>0.05$ \\
\hline
\end{tabular}

Values are number of patients (\%). $n$ - 40 for each group.

PACU - post anaesthetic care unit.

$* P$ value using $3 \times 2 \chi^{2}$ test followed by $2 \times 2 \chi^{2}$ test.

Figure 1: Requirement of rescue antiemetics

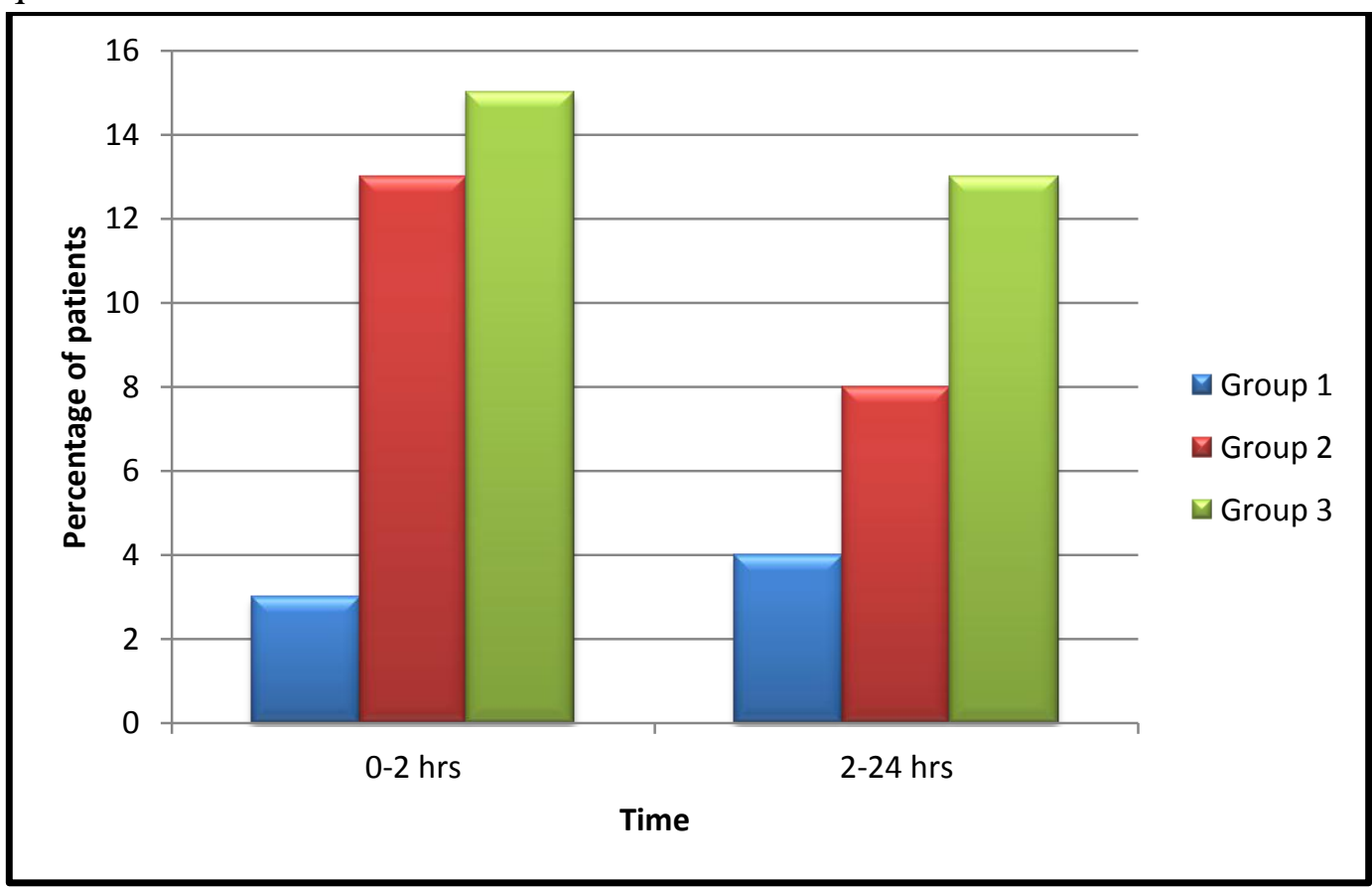

\section{Discussion}

The multimodal approach of using more than one antiemetic was initially described due to the limited effects of single-drug therapy. Multiple drug therapies resulted in a lower incidence of PONV. ${ }^{(17)}$ While numerous trials had validated the utility of this method, the point to be understood was that the multimodal approach extends far beyond intra operative pharmacotherapy. It starts with non-pharmacological interventions in the preoperative area itself. ${ }^{(18)}$

Dexamethasone was effective in reducing the incidence of postoperative nausea and vomiting (PONV) in patients undergoing adenotonsillectomy, thyroidectomy, cholecystectomy, and abdominal hysterectomy. ${ }^{(19,20)}$ Despite this antiemetic effect, the optimal timing of dexamethasone administration on its efficacy as a prophylactic antiemetic on PONV had not been previously studied. This study was designed to test the hypothesis that dexamethasone was more effective in preventing PONV when administered either before the induction of anaesthesia or at the end of anaesthesiawhen compared with a placebo.

Our study was to identify the prophylactic effect of dexamethasone in patients undergoing general anaesthesia which obviously included a wide range of surgeries. Since the incidence of PONV was high in certain type of surgeries, it became essential to rule out the differences among the groups regarding the type of the surgeries. The various type of surgeries done for the three groups were categorised under otolaryngologic, orthopaedic, laparoscopy, laparotomy and other surgeries. The results were tabulated and subjected to statistical analysis. It was found to have no statistical significance. 
After neutralising all the factors that could interfere with our study, we assessed the incidence of nausea and vomiting in patients for every 30 min during PACU stay and for every four hours in the ward. A total of $15 \%$ of patients in group 1, $50 \%$ of patients in group 2 and $52.5 \%$ of patients in group 3 experienced Nausea and vomiting during their stay in Post Anaesthesia care unit. Their $\mathrm{p}$ values were calculated. The $\mathrm{P}$ values were significant when Group 1 and Group 2 were compared, also when Group 1 and Group 3 were compared. The patients who received dexamethasone at the end of anaesthesia did not show any statistical significance when compared to that of placebo group.

A total of $17.5 \%$ of patients in Group 1, 32.5\% of patients in Group 2 and 50\% of patients in Group 3 had nausea and vomiting during their stay in the ward for 24 hours. Their $p$ values were calculated. The $\mathrm{P}$ values were significant when the patients who received dexamethasone before induction of anaesthesia and the patients who received dexamethasone at the end of anaesthesia were compared. The $\mathrm{p}$ values were also significant when Group 1 and Group 3 were compared. The patients who received dexamethasone at the end of anaesthesia did not show any statistical significance when compared to that of placebo group.

Overall $17.5 \%$ of patients in group 1, 52.5\% patients in group 2 and $70 \%$ patients in group 3 received rescue anti emetics. The $\mathrm{p}$ values were found to be significant when Group 1 was compared to that of Group 2 and Group3 respectively. There was no statistical difference between Group 2 and group 3. These findings were very much similar to the study done by Murphy et al ${ }^{(21)}$, Gomez et al ${ }^{(22)}$ and $\mathrm{Wu}$ et al. ${ }^{(23)}$ Murphy et al studied the use of pre operative dexamethasone in patients undergoing cholecystectomy surgeries. Gomez et al studied the use of pre operative dexamethasone in patients undergoing mastectomy and $\mathrm{Wu}$ et al studied the prophylactic effect of dexamethasone in patients undergoing anorectal surgeries. All these three studies had similar study design as our study and the results obtained were very much similar to our study.

Cost was an ever-increasing concern in today's healthcare system. The antiemetics we use in our day to day practice were relatively expensive when compared to dexamethasone. Further dexamethasone was supplied free of cost in our institution. The long-term administration of corticosteroids causes side effects such as additional wound infection, glucose intolerance, adrenal suppression, superficial ulceration of gastric mucosa, and delayed healing. However, a single dose of dexamethasone was considered safe. Since we used only a single dose of dexamethasone, we didnot expect any side effects related to dexamethasone. Further any of the patients did not report any side effects like headache, dizziness or sedation. Thus we justify the use of dexamethasone for the prevention of PONV in our study.

\section{Conclusion}

In conclusion, the prophylactic administration of 8 $\mathrm{mg}$ of IV dexamethasone, before the induction of anaesthesia, was more effective than at the end of anaesthesia for preventing PONV in patients undergoing surgeries under general anaesthesia.

\section{References}

1. Macario A,Weinger M, Carney S, Kim A. Which clinical anesthesia outcomes are important to avoid? The perspective of patients. AnesthAnalg 1999; 89: 652-8.

2. MacarioA,Weinger M, Truong $\mathrm{P}$, Lee $\mathrm{M}$. Which clinical anesthesia outcomes are both common and important to avoid? The perspective of a panel of expert anesthesiologists. AnesthAnalg 1999; 88: 1085-91.

3. Apfel CC, Heidrich FM, Jukar-Rao S, Jalota L, Hornuss C, Whelan RP, Zhang K, Cakmakkaya OS. Evidence-based analysis of risk factors for postoperative nausea and vomiting. Br J Anaesth 2012;109:742-53. 
4. Apfel CC, Läärä E, Koivuranta M, Greim CA, Roewer N. A simplified risk score for predicting postoperative nausea and vomiting: conclusions from crossvalidations between two centers. Anesthesiology 1999;91:693-700.

5. Koivuranta M, Läärä E, Snåre L, Alahuhta S. A survey of postoperative nausea and vomiting. Anaesthesia 1997;52:443-9.

6. Sinclair DR, Chung F, Mezei G. Can postoperative nausea and vomiting be predicted? Anesthesiology 1999;91:109-18.

7. Hill RP, Lubarsky DA, Phillips-Bute B, Fortney JT, Creed MR, Glass PS, Gan TJ. Cost-effectiveness of prophylactic antiemetic therapy with ondansetron, droperidol, or placebo. Anesthesiology 2000;92:958-67.

8. Tramèr MR. Strategies for postoperative nausea and vomiting. Best Pract Res ClinAnaesthesiol 2004;18:693-701.

9. Gan TJ, Meyer TA, Apfel CC, Chung F, Davis PJ, Habib AS, Hooper VD, Kovac AL, Kranke P, Myles P, Philip BK, Samsa G, Sessler DI, Temo J, Tramèr MR, Vander Kolk C, Watcha M; Society for Ambulatory Anesthesia. Society for Ambulatory Anesthesia guidelines for the management of postoperative nausea and vomiting. AnesthAnalg 2007;105:161528.

10. ASPAN'S evidence-based clinical practice guideline for the prevention and/or management of PONV/PDNV. J PerianesthNurs 2006;21:230-50.

11. McCracken G, Houston P, Lefebvre G; Society of Obstetricians and Gynecologists of Canada. Guideline for the management of postoperative nausea and vomiting. $\mathbf{J}$ ObstetGynaecol Can 2008;30:600-7,60816

12. Baxendale BR, Vater M, Lavery KM. Dexamethasone reduces pain and swelling following extraction of third molar teeth. Anaesthesia 1993;48:961-4.
13. Wang JJ, Ho ST, Lee SC, et al. The prophylactic effect of dexamethasone on postoperative nausea and vomiting in women undergoing thyroidectomy: a comparison of droperidol with saline. AnesthAnalg 1999;89:200 -3.

14. Fujii Y, Tanaka H, Toyooka H. The effects of dexamethasone on antiemetics in female patients undergoing gynecologic surgery. AnesthAnalg 1997;85:913-7.

15. Pappas ALS, Sukhani R, Hotaling AJ, et al. The effect of preoperative dexamethasone on the immediate and delayed postoperative morbidity in children undergoing adeno-tonsillectomy. AnesthAnalg 1998;87:57-61.

16. Wang JJ, Ho ST, Liu YH, et al. Dexamethasone reduces nausea and vomiting after laparoscopic cholecystectomy. $\mathrm{Br} \quad \mathrm{J}$ Anaesth 1999;83:772-5.

17. Eberhart LH, Morin AM, Bothner U, Georgieff M. Droperidol and 5-HT3receptor antagonists, alone or in combination, for prophylaxis of postoperative nausea and vomiting. A meta-analysis of randomised controlled trials. ActaAnaesthesiol Scand 2000; 44: 1252-7.

18. Gan TJ, Meyer TA, Apfel CC, et al. Society for Ambulatory Anesthesia guidelines for the management of postoperative nausea and vomiting. AnesthAnalg 2007; 105: 1615-28, table of contents.

19. Splinter WM, Roberts DJ. Prophylaxis for vomiting by children after tonsillectomy: dexamethasone versus perphenazine. AnesthAnalg 1997;85:534 -7.

20. Fujii Y, Tanaka H, Toyooka H. The effects of dexamethasone on antiemetics in female patients undergoing gynecologic surgery. AnesthAnalg 1997;85:913-7.

21. Murphy GS, Szokol JW, Greenberg SB, Avram MJ, Vender JS, Nisman M, Vaughn J. Preoperative dexamethasone enhances quality of recovery after 
laparoscopic cholecystectomy: effect on in-hospital and postdischarge recovery outcomes. Anesthesiology 2011;114:88290.

22. Gómez-Hernández J, Orozco-Alatorre AL, Domínguez- Contreras M, OcegueraVillanueva A, Gómez-Romo S, Alvarez Villaseñor AS, Fuentes-Orozco C, González-Ojeda A. Preoperative dexamethasone reduces postoperative pain, nausea and vomiting following mastectomy for breast cancer. BMC Cancer 2010;10:692.

23. Wu JI, Lu SF, Chia YY, Yang LC, Fong WP, Tan PH. Sevoflurane with or without antiemetic prophylaxis of dexamethasone in spontaneously breathing patients undergoing outpatient anorectal surgery. J ClinAnesth 2009;21:469-73. 